\title{
ENSINO EM GRUPO E DEBATE PARA A APRENDIZAGEM DE TEORIAS RELACIONADAS À ORIGEM DA VIDA E EVOLUÇÃO BIOLÓGICA NOS $3^{\circ}$. ANOS DO ENSINO MÉDIO DA E. E. PIRASSUNUNGA, SP
}

PEDROSO-DE-MORAES, Cristiano ${ }^{1}$ CAMARGO, Diogenes Rafael $\mathrm{de}^{2}$ ARAÚJO NETO, João ${ }^{3}$

CECHINATO, Loiana Rita Marcolino Rosa ${ }^{4}$ PINHEIRO, Rogério de Camargo ${ }^{5}$

\begin{abstract}
RESUMO: Considera-se que cabe ao ensino de Biologia (Ciências da Natureza) no Brasil, dotar os alunos de chaves essenciais para a solução de questões científicas e técnicas do cotidiano relacionadas a temas de cunho filosóficos, sendo que dentre essas questões, encontram-se discussões sobre as teorias relacionadas à origem da vida e processos evolutivos, assuntos interligados e permeados por crenças, dogmas e ideologias que, caso não passem por um amplo e delicado planejamento e reflexão por parte do docente, podem gerar controvérsias e discussões não dialéticas em sua abordagem em salas de aula. Por meio da utilização das metodologias de Ensino em Grupos e Discussões e Debates, a intervenção pedagógica realizada propiciou uma aprendizagem ativa, promovendo com dinamismo, eficiência e eficácia conhecimentos sobre os temas origem da vida (Criacionismo, Panspermia, Design Inteligente) e Evolucionismo (Lamarckismo, Darwinismo e Neodarwinismo ou Teoria Sintética da Evolução). Também, notou-se ao final do projeto melhoria nas competências leitora e escritora. Contudo, ainda há necessidade de se aprofundar técnicas de leitura filosófica e interpretação de texto com os discentes. Os partícipes do projeto também demonstraram preocupação com a continuidade do projeto para os futuros colegas, evidenciando, princípios norteadores de cidadãos conscientes e responsáveis socialmente.
\end{abstract}

Palavras-chave: Autorregulação da aprendizagem. Ensino-aprendizagem. Ensino de Biologia.

SUMMARY: (Teaching in group and debate for the learning of theories related to the origin of life and biological evolution in the 3rd. years of High School of E. E. Pirassununga, SP.). It is considered that it is the teaching of Biology (Natural Sciences) in Brazil, to provide the students with keys essential for the solution of scientific and technical questions of everyday life related to socio-philosophical subjects, among which are discussions on theories related to the origin of life and evolutionary processes, interrelated subjects and permeated by beliefs and ideologies that, if they do not go through a wide and delicate planning by the teacher, can generate controversies and discussions in their approach in classrooms. Using the methodologies of Teaching in Groups and Discussions and Debates, the pedagogical intervention provided an active learning, promoting with dynamism, efficiency and effectiveness knowledge about the themes origin of life (Creationism, Panspermia, Intelligent Design) and Evolutionism (Lamarckism, Darwinism and Neo-Darwinism or Synthetic Theory of Evolution). Also, it was noted at the end of the project improvement in reading and writing skills. However, there is still a need to deepen text interpretation techniques with students. The project participants also expressed concern about the continuity of the project for future colleagues, highlighting guiding principles of conscientious and socially responsible citizens.

Keywords: Self-regulation of learning. Teaching-learning. Teaching of biology.

\footnotetext{
${ }^{1}$ Prof. de Botânica e Ecologia Uniararas

${ }^{2}$ Técnico de Laboratório do Curso de Biologia Uniararas - Mestre em Educação pela Unesp/RC

${ }^{3}$ Vice-Diretor da Escola Estadual Pirassununga - SEE/SP - Prof. de Biologia - Vice-Diretor da Escola Estadual Pirassununga - SEE/SP

${ }^{4}$ Diretora da Escola Estadual Pirassununga - SEE/SP

${ }^{5}$ Prof. Coordenador da Escola Estadual Pirassununga - SEE/SP -

Prof. de Linguagem e Prof. Coordenador da Escola Estadual Pirassununga - SEE/SP
} 


\section{INTRODUÇÃO}

A docência se caracteriza pelo permanente desafio de estabelecer relações interpessoais com discentes, permitindo que o processo de ensino-aprendizagem ocorra de forma eficaz e eficiente e que os métodos utilizados cumpram os objetivos a que se propõem (MAZZIONI, 2013) principalmente, com relação à autorregulação da aprendizagem no ensino de Biologia (PEDROSO-DE-MORAES et al., 2015).

Para o Ensino Médio (EM), o Ministério da Educação nos Parâmetros Curriculares Nacionais (PCN) (BRASIL, 1999) introduziu reformas curriculares visando estabelecer diretrizes proposicionais de conteúdos capazes de atender às necessidades das profundas mudanças sociais, econômicas, políticas, ambientais e culturais ocorrentes no mundo (MARTINS, 2000). Tais adequações advêm da necessidade de ações globalizantes que seguem as tendências reformistas ocorrentes em diferentes países em relação à educação, tema que vem ocupando vários teóricos da área das ciências sociais, humanas e naturais (MARTINS, 2000). Processos educativos relacionados a metodologias educacionais ativas proveem educandos com conhecimentos, habilidades e competências que os permitem participação de debates relacionados a temas globais e também, propiciam a formação de cidadãos participativos em suas relações sociais locais (SILVA; CARVALHO, 2002).

Sob este aspecto, os procedimentos de ensino geram consequências para a prática docente (LUCKESI, 1994), pois para se definir procedimentos e metodologias de ensino de forma precisa, o docente necessita de uma proposta pedagógica clara e concisa, além de compreender que os procedimentos pedagógicos selecionados e/ou construídos são mediações da proposta pedagógicoeducacional e que também permeiam o método de ensino, devendo estes dois componentes estar estreitamente articulados (MAZZIONI, 2013).

Métodos educativos ativos podem ser utilizados por si só, ou em conjunto, visando práxis mais eficiente (PEDROSO-DE-MORAES et al., 2015). Entre a variada gama de metodologias ativas listadas podem ser citadas como de elevada eficiência e facilidade de utilização em salas de aula, o Ensino em Grupos e a Discussão e Debate (MAZZIONI, 2013). O Ensino em Grupos "é uma estratégia particularmente válida em grandes turmas, pois consiste em separar a turma em pequenos grupos, para facilitar a discussão. Assim, despertará no aluno a iniciativa de pesquisar, de descobrir aquilo que precisa aprender" (PETRUCCI; BATISTON, 2006, p. 278-279). Em relação a Discussão e Debate, "tal metodologia sugere aos educandos a reflexão acerca de conhecimentos obtidos após uma leitura ou exposição, dando oportunidade para a formulação de princípios com suas próprias palavras, e sua posterior aplicação" (MARION; MARION, 2006, p. 42-44).

Neste sentido, para o Brasil, considera-se que cabe ao ensino de Biologia (Ciências da Natureza), dotar os alunos de chaves essenciais para a solução de questões científicas e técnicas do cotidiano relacionadas a temas de cunho filosóficos (ASTOLFI; DEVELAY, 1998; SAVIANI, 2000; SILVA; CARVALHO, 2002; MENDONÇA et al., 2008, CAMARGO, 2016), sendo que dentre essas questões, encontram-se discussões sobre as teorias relacionadas à origem da vida e processos evolutivos, assuntos interligados e permeados por crenças e ideologias que, caso não passem por um amplo e delicado planejamento e reflexão por parte do docente, podem gerar controvérsias e acaloradas discussões não dialéticas em sua abordagem em salas de aula (MARTINS, 2013).

Sob tais perspectivas educacionais, filosóficas e étnico teológicas, portanto, inter e transdiciplinares, o presente trabalho teve por objetivo propiciar uma aprendizagem ativa por meio da utilização das metodologias de Ensino em Grupos e Discussões e Debates com a finalidade de promover o conhecimento sobre os temas origem da vida (Criacionismo, Panspermia, Design Inteligente) e 
Evolucionismo (Lamarckismo, Darwinismo e Neodarwinismo ou Teoria Sintética da Evolução) com os alunos dos $3^{\circ}$. anos A, B e C do Ensino Médio da Escola Estadual Pirassununga, em Pirassununga - SP.

\section{MATERIAL E MÉTODO}

$\mathrm{O}$ projeto foi desenvolvido junto aos alunos das $3^{\mathrm{a}}$. Séries A, B e C do Ensino Médio da Escola Estadual Pirassununga, vinculada à Diretoria de Ensino de Pirassununga, SP, durante o $1^{\circ}$. Bimestre de 2017 (fevereiro-março). O desenvolvimento do projeto ocorreu com a participação de 78 alunos e teve duração de oito horas-aula.

Primeiramente, foi solicitado aos alunos a formação de quatro grupos por sala. Os grupos foram montados com um número de cinco ou seis discentes. Cada um dos grupos recebeu três folhas de almaço e uma de sulfite para a realização do trabalho, sendo que informações sobre os temas selecionados foram pesquisadas e trazidas previamente pelos alunos, conforme combinado anteriormente com o docente. $\mathrm{O}$ trabalho foi estruturado da seguinte forma: Capa (feita em folha de sulfite), Introdução (contendo informações gerais sobre a importância do desenvolvimento do tema, tais como mitos de criação da humanidade, hipótese autótrofa, hipótese heterótrofa, abiogênese e biogênese), Desenvolvimento (contendo informações sobre o Criacionismo, Panspermia, Evolucionismo e Design Inteligente), Conclusão e Referências. A duração da realização do trabalho em grupo foi de 4 horas-aula. Posteriormente, os grupos escolheram democraticamente um dos seguintes temas: Criacionismo, Panspermia, Evolucionismo e Teoria do Design Inteligente. Tais temas foram explorados durante a realização de um debate em sala, com duração de 4 horas-aulas. O debate foi mediado pelo docente da disciplina e foi estruturado da seguinte maneira. Explanação Inicial - cada grupo teve até 10 minutos para apresentar seu tema. Arguição - cada grupo teve de responder duas perguntas formuladas por cada grupo e pelo docente, em um total de seis advindas dos colegas de sala e duas do professor. O professor avaliou a coerência, relevância e oralidade tanto das respostas quanto das perguntas formuladas. Para cada pergunta formulada pelos colegas e pelo professor, o grupo a responder, teve tempo de 5 minutos para organizar e elaborar suas respostas. Somente material prévio, escrito e impresso pôde ser consultado para a elaboração das respostas. Réplica - nessa fase, os grupos tiveram 5 minutos para reafirmar a importância de seus postulados e realizar correções de erros cometidos na explanação inicial e/ou nas respostas dadas as perguntas. Os grupos também puderam nesta etapa criticar e demonstrar formas antagônicas de pensamento a respeito dos conceitos defendidos pelos colegas que defendiam as demais teorias. Tréplica - nesta etapa final, os grupos tiveram 5 minutos para realizar uma defesa teórica final da importância dos conceitos por eles explanados.

Em suma, foi avaliado pelo professor durante e ao final da intervenção: a integração de todos os alunos no grupo, domínio de teoria e capacidade de explanação e defesa de causa (respostas coerentes em relação às perguntas dos outros grupos e convencimento da importância de sua teoria). Ao final, erros conceituais foram apontados e corrigidos pelo docente.

Ressalta-se que todos os conceitos abordados estão de acordo com a Proposta Curricular do Estado de São Paulo (MENDONÇA et al., 2008).

Este trabalho foi fundamentado em uma pesquisa quali-quantitativa participativa como procedimento metodológico, enquadrando-se aos propósitos iniciais da pesquisa para a consecução de seus objetivos (PEDROSO-DE-MORAES et al., 2015). Desta forma, foi utilizada a modalidade pesquisa-ação, por ser capaz de proporcionar a manifestação do coletivo (SILVA et al., 2014). Pode-se dizer que a pesquisa-ação é caracterizada como um tipo de pesquisa social com base empírica, concebida e realizada em estreita associação com uma ação ou com a resolução de um problema coletivo; a pesquisa não se limita à ação, 
pressupõe um aumento do conhecimento e do nível de consciência das pessoas ligadas à situação e do próprio pesquisador (THIOLLENT, 2000).

No intuito de avaliar a aprendizagem após a execução do projeto dentro da inter e da transdisciplinaridade, foi elaborado um questionário com questões objetivas respondido pelos alunos uma semana após o término dos trabalhos em grupo e do debate, e corrigido pelo professor (SENICIATO; CAVASSAN, 2004; PEDROSO-DE-MORAES et al., 2015). Tal questionário foi subdividido em três partes:

Parte I - conteúdo apresentado no trabalho em grupo e no debate, para a verificação da aprendizagem de conteúdo especifico (utilização de questões objetivas) (Quadro I).

Parte II - aplicação e estrutura do projeto, para a avaliação por parte dos discentes (questões objetivas) (Quadro II).

Parte III - Avaliação do projeto, por meio de competência escritora, pela realização por parte dos discentes de uma mini redação (Quadro II).

Todos os resultados obtidos quantificáveis foram expressos em porcentagem e disponibilizados em gráficos. Quanto à produção de texto, foi observado pelo docente: coerência quanto ao tema e as regras de utilização da norma culta (PEDROSO-DE-MORAES et al., 2015).

QUESTÕES formuladas para a avaliação do conteúdo apresentado no trabalho em grupo e no debate ministrados aos alunos do dos $3^{\text {os }}$. Anos A, B, C do Ensino Médio da Escola Estadual Pirassununga, São Paulo.

\section{Questões}

1 - Pode-se dizer que o criacionismo se caracteriza pela defesa do seguinte argumento:

a) todas as espécies de seres vivos existentes evoluíram ao logo do tempo, seguindo as leis da seleção natural.

b) a vida, o universo e todos os seres existentes não passaram a existir do nada sem que houvesse um ser superior e eterno que os tivesse concebido inteligentemente.

c) o desenvolvimento da vida e da grande diversidade de seres vivos independe de algo externo à materialidade da existência.

d) nenhum ser vivo pode ser tido como membro de uma espécie independentemente das leis da seleção natural.

e) Richard Dawkins, zoólogo britânico, contribui atualmente para o endosso do criacionismo, haja vista que acredita na existência de uma lógica sobrenatural no curso da vida na Terra.

2 - "O mundo seria ordenado demais, harmonioso demais, para que se possa explicá-lo sem supor, na sua origem, uma inteligência benevolente e organizadora. Como o acaso poderia fabricar um mundo tão bonito? Se encontrassem um relógio num planeta qualquer, ninguém poderia acreditar que ele se explicasse unicamente pelas leis da natureza, qualquer um veria nele o resultado de uma ação deliberada e inteligente. Ora, qualquer ser vivo é infinitamente mais complexo do que o relógio mais sofisticado. Não há relógio sem relojoeiro, diziam Voltaire e Rousseau. Mas que relógio ruim o que contém terremotos, furacões, secas, animais carnívoros, um sem-número de doenças - e o homem! A história natural não é nem um pouco edificante. A história humana também não. Que Deus após Darwin? Que Deus após Auschwitz?" (André Comte-Sponville. Apresentação da filosofia, 2002. Adaptado.)

Sobre os argumentos discorridos pelo autor, é correto afirmar que a existência de Deus é:

a) defendida mediante um argumento de natureza estética, em oposição ao caráter ideológico e alienante das crenças religiosas.

b) tratada como um problema sobretudo metafísico e teológico, diante do qual são irrelevantes as questões empíricas e históricas.

c) abordada sob um ponto de vista bíblico-criacionista, em oposição a uma perspectiva romântica peculiar ao iluminismo filosófico. 
d) problematizada mediante um argumento de natureza mecanicista-causal, em oposição ao problema ético da existência do mal.

e) tratada como uma questão concernente ao livre-arbítrio da consciência, em detrimento de possíveis especulações filosóficas.

3 - Considere as frases a seguir.

A "Afinal, o que é o homem dentro da natureza? [...]

é-lhe impossível ver o nada de onde saiu e o infinito que o envolve.[...]

$\mathrm{O}$ autor destas maravilhas conhece-as; e ninguém mais". (Blaise Pascal)

B "A antiga aliança rompeu-se. O homem sabe, finalmente, que está só na imensidade indiferente do universo, donde emergiu por acaso. Nem o seu destino nem o seu dever estão escritos em parte alguma". (Jacques Monod)

$\mathrm{C}$ "[...] a vida foi aqui lançada com microrganismos que teriam vindo nalguma forma de nave espacial enviada por uma civilização superior". (Francis Crick)

Assinale a alternativa que indica, corretamente, as frases que expressam, respectivamente, as posições em defesa de: criacionismo, panspermia e evolucionismo.

a) A, B, C.

b) A, C, B.

c) $\mathrm{B}, \mathrm{A}, \mathrm{C}$.

d) B, C, A.

e) C, A, B.

4 - Considerando as teorias mais aceitas atualmente para a origem da vida e o início da história dos seres vivos, considere as seguintes afirmativas:

1. A simbiose teve papel relevante na origem dos eucariontes.

2. A diversidade de funções desempenhadas pelo RNA leva a crer que este tenha sido precursor do DNA.

3. Organismos multicelulares, como as plantas, foram responsáveis pelo início do grande aumento da concentração de oxigênio na atmosfera terrestre.

4. A existência do oxigênio na atmosfera terrestre foi imprescindível para o surgimento da vida.

Assinale a alternativa correta:

a) Somente as afirmativas 1 e 3 são verdadeiras.

b) Somente as afirmativas 2 e 4 são verdadeiras.

c) Somente as afirmativas 1, 2 e 4 são verdadeiras.

d) Somente as afirmativas 3 e 4 são verdadeiras.

e) Somente as afirmativas 1 e 2 são verdadeiras.

5 - A ideia criacionista relacionada à origem do ser humano predominou nas sociedades ocidentais cristãs até o século dezenove. Durante muito tempo de estudos o cientista Charles Darwin lançou o livro "A origem das espécies", no qual propôs:

a) O reforço do criacionismo

b) $\mathrm{O}$ evolucionismo

c) $\mathrm{O}$ cristianismo

d) A seleção natural

e) A patologia humana

6 - Para Charles Darwin o mecanismo biológico que faz as espécies se modificarem, evoluírem e se diferenciarem é:

a) A seleção natural

b) $\mathrm{O}$ criacionismo

c) A natureza 
d) $\mathrm{O}$ ambiente

e) O bioma

7 - É comum ouvirmos pessoas falando erroneamente que Darwin afirmou que o homem veio do macaco. Diferentemente do que muitos dizem, Darwin apenas explicou que em algum momento no passado todos nós compartilhamos um ancestral. Baseando-se nessa afirmação e nos seus conhecimentos sobre o darwinismo, marque a alternativa que indica corretamente duas ideias centrais da teoria evolucionista proposta por Darwin.

a) Lei do uso e desuso e lei da herança dos caracteres adquiridos.

b) Seleção natural e fluxo gênico

c) Ancestralidade comum e seleção natural.

d) Seleção natural e lei da herança dos caracteres adquiridos.

e) Ancestralidade comum e lei do uso e desuso.

8 - Quando Darwin propôs sua teoria, o conhecimento em Genética era precário, o que deixou várias lacunas em seu trabalho. Após alguns anos com conhecimentos mais avançados nessa área da Biologia, complementou-se a teoria de Darwin como os conhecimentos adquiridos em Genética, sendo possível explicar os fatores evolutivos. Essa teoria ficou conhecida como:

a) Darwinismo.

b) Fixismo.

c) Gradualismo filético.

d) Neodarwinismo.

AVALIAÇÃO da metodologia empregada na intervenção pedagógica realizada por parte dos alunos dos $3^{\text {os }}$. Anos A, B, C do Ensino Médio da Escola Estadual Pirassununga-SP

\section{Analise se as afirmações e responda:}

1 - Em relação ao conteúdo pesquisado e debatido no projeto abordando às teorias relacionadas à origem da vida e evolução, sua realização permitiu uma aprendizagem mais dinâmica e eficiente.

a) Concordo plenamente

b) Concordo parcialmente

c) Discordo

2 - O tempo utilizado para a realização do projeto ( 8 horas-aulas: 4 para o trabalho em grupo e 4 para o debate), foram suficientes para uma plena aprendizagem.

a) Concordo plenamente

b) Concordo parcialmente

c) Discordo

3 - A obrigatoriedade no trabalho em grupo da presença de todas as teorias permitiu que os alunos aprendessem sobre crenças e teorias científicas, o que permitiu um debate mais amplo e eficiente.

a) Concordo plenamente

b) Concordo parcialmente

c) Discordo

4 - A estrutura do debate em Explanação Inicial, Arguição, Réplica e Tréplica permitiram uma intervenção pedagógico-educacional organizada e eficiente.

a) Concordo plenamente 
b) Concordo parcialmente

c) Discordo

5 - Por meio de uma mini redação, dê sua opinião sobre a realização do projeto, pensando em cada etapa: trabalho escrito e debate. Aponte pontos fortes e falhas a serem melhoradas.

\section{RESULTADO E DISCUSSÃO}

Os resultados obtidos em relação ao desempenho dos alunos na avaliação demonstram boa assimilação em relação aos conteúdos ministrados, com a maior parte das questões apresentando acerto acima de 50\%. Somente as questões números 02, 04 e 07 obtiveram índice de acerto insatisfatório (Tabela 1). Portanto, os percentuais de acerto da maioria das questões evidenciam o sucesso da intervenção pedagógica, fato também atestado pelo reflexo positivo obtido (resultados auferidos) nas respostas relacionadas à avaliação da metodologia empregada, realizada pelos alunos (Tabela 2).

Tabela 1 - Porcentagens de acertos relacionados às questões do conteúdo ministrado na intervenção pedagógica realizada para os alunos dos $3^{\mathrm{o}}$. Anos A, B e C do Ensino Médio da Escola Estadual Pirassununga, SP.

\begin{tabular}{|c|c|c|c|c|}
\hline Questões & Acerto $3^{\circ}$. A (\%) & Acerto $3^{\circ}$. B (\%) & Acerto $3^{\circ} . \mathrm{C}(\%)$ & Acertos totais $(\%)$ \\
\hline 1 & 79,2 & 65,5 & 68 & 70,5 \\
\hline 2 & 45,8 & 6,9 & 20 & 21,8 \\
\hline 3 & $\mathbf{7 0 , 8}$ & 34,5 & 32 & 56,4 \\
\hline 4 & 20,8 & 6,9 & 12 & 12,8 \\
\hline 5 & 66,6 & 82,7 & 92 & 80,8 \\
\hline 6 & 62,5 & 48,3 & 52 & 53,8 \\
\hline 7 & 33,4 & 27,6 & 32 & $\mathbf{3 0 , 8}$ \\
\hline 8 & 62,5 & 41,4 & 64 & 51,1 \\
\hline
\end{tabular}


Tabela 2 - Porcentagens obtidas em relação às questões da avaliação da metodologia empregada na intervenção pedagógica realizada pelos os alunos dos $3^{\text {os }}$ Anos A, B e C do Ensino Médio da Escola Estadual Pirassununga, SP.

\begin{tabular}{|c|c|c|c|c|c|c|c|c|c|c|c|c|}
\hline \multirow[t]{2}{*}{ Questões } & \multicolumn{3}{|c|}{ Acerto $3^{\circ} . \mathbf{A}(\%)$} & \multicolumn{3}{|c|}{ Acerto $3^{\circ}$. B (\%) } & \multicolumn{3}{|c|}{ Acerto $3^{\circ} . \mathrm{C}(\%)$} & \multicolumn{3}{|c|}{ Acertos totais (\%) } \\
\hline & $\underline{\mathbf{A}}$ & B & C & $\underline{\mathbf{A}}$ & B & $\mathrm{C}$ & $\underline{\mathbf{A}}$ & B & C & $\underline{\mathbf{A}}$ & B & $\underline{\mathbf{C}}$ \\
\hline 1 & 83,3 & 16,7 & - & 65,5 & 34,5 & - & 76 & 24 & - & $\mathbf{7 4 , 4}$ & 25,6 & - \\
\hline 2 & 91,6 & 4,2 & 4,2 & $\begin{array}{l}82,5 \\
2,1\end{array}$ & & 13,5 & 80 & 16 & 4 & 85,9 & 10,3 & 38,8 \\
\hline 3 & 91,6 & 8,4 & - & $\begin{array}{l}\mathbf{7 2 , 4} \\
\mathbf{3 , 5}\end{array}$ & & 24,1 & 88 & 12 & - & 83,3 & 15,4 & 1,3 \\
\hline 4 & 79,2 & 20,8 & - & $\begin{array}{l}65,5 \\
6,9\end{array}$ & & 27,6 & 88 & 12 & - & 76,9 & 20,5 & 2,6 \\
\hline
\end{tabular}

Com relação às questões com bom índice de acerto, pôde-se inferir nas análises dos resultados que as principais definições e conceitos a respeito do Criacionismo, Design Inteligente, Evolucionismo e Panspermia (Quadro 1) foram fixados pelos alunos (Tabela 1 - acertos totais). Nesse contexto, é importante lembrar-se que:

Muito já se escreveu sobre os erros conceituais em que incorrem os criacionistas em sua polêmica com o darwinismo, bem como sobre a ausência de um programa de pesquisa, no interior de suas doutrinas, que permita qualquer avanço no âmbito das ciências da vida. Bem menos pesquisado, porém, é o contexto histórico e social que viabilizou a expansão dos criacionistas e do seu desdobramento mais recente, o assim chamado design inteligente (MARTINS, 2013, p.280).

O bom desempenho na assimilação dos conteúdos permitida pela metodologia empregada e, principalmente, pela pluralidade temática utilizada no desenvolvimento do projeto, é corroborada pela intervenção análoga realizada com alunos dos $3^{\text {os }}$. Anos do Ensino Médio de Escola Pública do Município de Guarulhos, SP., na qual foram encontrados resultados semelhantes (MADEIRA, 2007). Sabe-se que devido à importância histórico-cultural e a atualidade das questões e controvérsias quanto à origem do Universo, da existência da vida e da humanidade, discutir o grau de conhecimento sobre às teorias relacionadas à origem da vida e evolução, bem como, suas formas de entendimento, são importantíssimas, principalmente, nas escolas (MADEIRA, 2007; MARTINS, 2013). Ressalta-se, também, que o ensino aprofundado dos conceitos sobre evolução, são extremamente relevantes academicamente, uma vez que constituem conteúdo frequente e amplamente explorado no Exame Nacional do Ensino Médio (ENEM) (PEDROSO-DE-MORAES et al., 2016).

Quando observamos o desempenho por sala, evidencia-se que a turma $3^{\circ}$. A, apresentou o maior percentual de acertos das questões em relação as outras duas salas. Durante a intervenção, segundo o professor, a turma apresentou o maior interesse e comprometimento em relação à autorregulação da aprendizagem, demonstrando verdadeiro protagonismo na busca do conhecimento e em sua formação cidadã, permitindo assim, que o docente assumisse seu verdadeiro papel de mediador do conhecimento. Tal observação está de acordo com a afirmação dos discentes de que:

O trabalho foi realizado em sala de aula e ajudou todos os alunos a tirar suas dúvidas sobre os temas abordados. Melhorou o aprendizado sobre Criacionismo, Panspermia, Evolucionismo e Design Inteligente. Cada tema tem uma teoria diferente, mas o debate 
que aconteceu durante as aulas, permitiu entender e debater sobre os temas. O Trabalho foi ótimo e muito bem preparado. Teve a colaboração de todos os alunos, cada um respeitando a opinião do próximo (Aluno $3^{\circ}$. A)

O trabalho que aconteceu em sala de aula, deu conhecimentos sobre religiões e teorias científicas que cada um deve aprender. Nesse trabalho, principalmente, no debate entre Panspermia e Criacionismo, aprendemos coisas muito interessantes. Nesse caso, os grupos dividiram conhecimentos e tiraram dúvidas (Aluna $3^{\circ}$. A).

Este projeto foi bastante eficiente e ajudou tanto no aprendizado do grupo quanto na união, pois tivemos que pesquisar, ouvir a opinião de cada um, aprender a respeitar opiniões diferentes. Todo mundo se empenhou ao máximo para realizar um ótimo debate. A única falha é ter somente duas aulas de Biologia por semana (Aluno $3^{\circ}$. A).

O projeto realizado foi bastante útil e de bastante importância, pois através dele, foi possível abrir a mente para novos aprendizados e também fortalecer a nossas ideias na teoria em que acreditamos. Um dos pontos que para mim foi o mais importante é que independente da crença de cada aluno, o debate proporcionou um respeito muito grande entre todos. Foi notório ao término do projeto uma compreensão entre todos na sala de aula. Foi evidente um amadurecimento de todos, pois, independente de qual teoria o homem acredite, antes de tudo é necessário que ele respeite a teoria ou crença que as pessoas que estão ao seu redor acreditam (Aluno $3^{\circ}$. A).

A intervenção também serviu, como observado nas falas acima, para o desenvolvimento de um ambiente de discussão, permeado por tolerância e aceite de convicções, "o que caracteriza a conjugação e a convivência de opiniões distintas...e apontam para uma adesão híbrida que se configura, numa nova forma de ressignificação de identidade fundamentalista em ambos os campos: Científico e Religioso" (MADEIRA, 2007, p.7). Contudo, diferentemente do observado para a turma supracitada, a análise de resultados permitiu auferir que o $3^{\circ}$. B, apresentou menor sucesso na assimilação do conteúdo do que as demais salas. Durante a intervenção foi relacionado e notado, por parte do docente, menor interesse e comprometimento dos alunos da sala em relação ao desenvolvimento do projeto, como salientado pelos próprios discentes componente da turma, na avaliação da intervenção:

Com uma melhor aprendizagem do conteúdo abordado os alunos puderam entender mais sobre as teorias que há anos os confundiam. Infelizmente com a falta de empenho de alguns, pontos do debate como a réplica e a tréplica deixaram a desejar, mostrando desinteresse pelo projeto. Apesar disso, alguns grupos se destacaram pela forma mais dinâmica e clara que explicaram suas teorias, causando melhor entendimento de todos (Aluno $3^{\circ}$. B).

O debate foi muito bem elaborado, mas deixou a desejar em relação às pesquisas dos grupos. Não se esforçaram muito para trazer um conteúdo mais aprofundado. Fora isso deu para aprender e compreender sobre as teorias. Foi uma intervenção pedagógica bem dinâmica e eficiente. (Aluno $3^{\circ}$. B).

O único ponto negativo foi a falta de comprometimento de alguns alunos em relação à entrega dos trabalhos e a saber mais sobre a pesquisa. Por fim, foi um ótimo trabalho e o professor contribuiu muito também (Aluna $3^{\circ}$. B).

Em relação à assimilação dos conteúdos, a turma $3^{\circ}$. C apresentou, segundo o docente, protagonismo intermediário, com apenas alguns alunos apresentando desinteresse pela intervenção, o que pode ser constatado pela percentagem de acertos das questões (Tabela 1). Tal observação é corroborada pela afirmação discente de que: 
É de consenso que a atividade foi de extrema importância para a fixação do conteúdo, trazendo um maior aprendizado. Sabe-se que a pesquisa ajuda os alunos a se empenhar. O debate aumentou ainda mais a aprendizagem, sendo que algo assim, jamais havia acontecido antes. Porém, para alguns alunos, a pesquisa em sala não despertou interesse, não sendo essa parte levada à sério por alguns. Portanto, pode-se concluir que mesmo com esse empecilho, o projeto fluiu e os conteúdos foram absorvidos (Aluna $3^{\circ}$. C).

Mesmo com a evidenciação de que para alguns alunos, a intervenção não se mostrou atrativa, para a grande maioria dos alunos, como pode ser observado na maior parte das falas anteriormente citadas, o projeto desenvolvido alcançou suas metas quanto ao desenvolvimento de habilidades e competências nos discentes.

O desenvolvimento de habilidades e competências no alunato, se dá, principalmente, pelo uso de estratégias de ensino-aprendizagem condizentes, permeadas pela eficiência, eficácia e dinamismo. Sob este aspecto, a utilização de técnicas pedagógicas e o desenvolvimento de procedimentos de ensino, deve levar em conta que a aprendizagem não é um ato isolado, escolhido aleatoriamente, sem prévia reflexão à cerca dos conteúdos a serem trabalhados, sem considerações sobre as prévias habilidades necessárias por parte dos discentes para a execução e participação em uma intervenção com a finalidade de se alcançar os objetivos propostos, o seja, o ensino (MAZZIONI, 2013). Sob tal perspectiva, a estrutura da intervenção pedagógica e a metodologia empregada em sua execução, foram concebidas de forma a permitir a integração e trabalho em equipe dos discentes, visando a autorregulação da aprendizagem por meio da formação de grupos de pesquisa, bem como, a utilização de debates para maior fixação dos conteúdos assimilados, caracterizando assim, sua aplicação como uma prática pedagógica eficiente, eficaz e dinâmica, como afirmado pelos alunos.

O trabalho aplicado foi muito bem escolhido, pois, se tratava de assuntos diversificados que tentam explicar a mesma coisa, que é origem da vida. $\mathrm{O}$ mais interessante e diferencial desse trabalho é que trouxe mais dinamismo às aulas e maneiras diferentes de se debater sobre um assunto. Este foi um trabalho que literalmente nos preparou para algo diferente e, caso venhamos ter que realizar outro deste, já teremos noção de como será (Aluno $3^{\circ}$. A).

O trabalho desenvolvido pode ser fortemente defendido diante do dinamismo e metodologia empregados para a aprendizagem. $\mathrm{O}$ debate permitiu que conhecêssemos diferentes opiniões e pontos de vista, a partir da ideia central apresentada, que também pode ser estudada a fundo por todos os alunos (Aluna $3^{\circ}$. A).

$\mathrm{O}$ debate nos mostrou muito sobre crenças e teorias. O meu conhecimento se aprofundou nisso. Fiquei muito interessado no assunto. Durante o debate, faltavam às vezes, algumas explicações dos grupos e isso me despertou mais interesse e curiosidade de saber mais. O trabalho escrito também nos ajudou muito, mais o debate foi diferente. Parece que você aprende mais. No debate você busca teorias e tentar provar que estas estão corretas. Isso faz pensar mais e duvidar mais, perguntando: será que foi desse jeito mesmo que o mundo surgiu? Acabam surgindo muitas dúvidas e a sede de conhecimento só aumentou e isso foi muito legal (Aluna $3^{\circ}$. A).

Ficou explicita a função pedagógica do debate que ajudou em questões de vestibulares de uma maneira mais dinâmica e eficaz. Conclui-se que apesar da necessidade de pequenos ajustes, o projeto deve continuar nos próximos anos em prol do conhecimento (Aluna $3^{\circ}$. B).

No que se refere à construção e realização do trabalho sobre evolução é possível afirmar que os alunos puderam não só aprender sobre os temas abordados, como também adquirir conhecimentos que são muito abrangentes e importantes para qualquer área de 
estudo. Isso se evidencia pela forma em que o trabalho foi feito e se positiva pelo satisfatório resultado. Segundo Darwin o mais adaptado é o que sobrevive. Essa afirmação pôde e poderá causar grande impacto, porque assim, como no trabalho, viu-se os prós e contras sobre essa afirmação. Dessa forma, os alunos puderam refletir e aprender teorias que são tão importantes como o respirar, porque de fato elas terminam por tentar explicar a criação e a formação de tudo. Todavia é dever dos alunos se preparem para estudar não só os temas determinados para cada grupo, como também os outros comentados em sala de aula, haja vista que são tão importantes quando os seus. (Aluna $3^{\circ}$. B).

Quando fazemos esse tipo de trabalho compreendemos melhor o assunto, pois este tipo de intervenção requer que o aluno pesquise, discuta com o seu grupo sobre o que é mais importante e o que não é e, assim, faça um debate com a sala. (Aluna $3^{\circ}$. C).

A metodologia do trabalho em si foi bem complexa. O tempo dado foi o suficiente, a organização dos grupos foi bem-sucedida. A pesquisa, sobre cada tema já permitiu um aprendizado, mas a presença do debate permitiu maior aprofundamento e aprendizagem ampla sobre as teorias científicas e crenças que permearam o debate. Um ponto que foi muito positivo, foi a união da sala em si e a dedicação dos alunos na pesquisa feita, no trabalho entregue e nos argumentos para o debate. O debate nos ajudou a mostrar o que tínhamos realmente aprendido, a mostrar o conhecimento adquirido através dessa metodologia (Aluna $3^{\circ}$. C).

O trabalho, toda a elaboração e apresentação, foi muito bem planejada pelo professor, e muito bem executada pelos alunos, que se aprofundaram nos temas, pesquisando não só o tema próprio, mas também as demais. Quanto a execução/apresentação, poderia ser mais longa, assim os alunos poderiam discutir mais e até propor algumas teorias. A obrigatoriedade de se fazer um grupo, foi essencial para uma concentração de ideias e argumentos fosse formada. A estrutura do debate foi uma ótima escolha, fazendo assim, com que surgissem dúvidas e respostas à altura" (Aluno $3^{\circ} . \mathrm{C}$ ).

Eu concordo que esse projeto fez com que desenvolvêssemos um conhecimento mais amplo, pois o que a maioria sabia sobre as Teorias da Vida e Evolução era apenas o básico e, com as pesquisas e debate em grupo em sala, trocamos informações e até tiramos dúvidas sobre conceitos que não estavam totalmente esclarecidos (Aluna $3^{\circ} . \mathrm{C}$ ).

"Procedimentos de ensino geram consequências para a prática docente: para se definir procedimentos de ensino com certa precisão, é necessário ter clara uma proposta pedagógica" (LUCKESI, 1994, p. 105). Neste caso é necessária a compreensão de que que os procedimentos de ensino escolhidos são mediações da proposta pedagógica e metodológica, devendo estar estreitamente articulados (MAZZIONI, 2013).

Se a intenção de uma intervenção é a efetivação da proposta pedagógica traduzida em resultados concretos, faz-se necessário selecionar um ou mais procedimentos metodológico-didáticos capazes de conduzir aos resultados esperados, ainda que parciais (LUCKESI, 1994; MAZZIONI, 2013). "Ao lado da proposta pedagógica, o educador deve lançar mão dos conhecimentos científicos disponíveis; estar permanentemente alerta para o que se está fazendo, avaliando a atividade e tomando novas e subsequentes decisões “(MAZZIONI, 2013, p.96). Sob este aspecto, em relação às propostas pedagógicas na intervenção utilizadas, temos que a união de pequenos grupos, permite a separação das turmas no intuito de facilitar a discussão e o despertar do protagonismo em relação à pesquisa que leva ao autodidatismo (PETRUCCI; BATISTON, 2006, p. 278-279), sendo que tal práxis permite sinergismo com o desenvolvimento de discussões em debates, o que leva os discentes à reflexões concernentes aos conteúdos assimilados após leituras, permitindo o desenvolvimento de definições próprias e a aplicabilidade de tais princípios (MARION; MARION, 2006, p. 42-44). Dessa forma, além de uma 
aprendizagem mais dinâmica, eficaz e eficiente dos conteúdos sócio biológicos obtidos pelos alunos nesta intervenção, paralelamente, ainda foi permitida o desenvolvimento e/ou aprofundamento das competências leitora e escritora, pois, uma das partes mais relevantes do trabalho foi a obrigatoriedade de entrega de um trabalho escrito contendo todas as teorias, posteriormente debatidas, o que permitiu a oportunidade de melhorias destas competências dos discentes partícipes do projeto. Tal desenvolvimento destas habilidade e competências, ainda, são importantíssimas, pois,

Segundo o Currículo do Estado de São Paulo a capacidade de leitura e escrita é de vital importante para o aluno e esse tema pode abrir brechas não só para um maior interesse na área de Ciências Biológicas como estimular os alunos na sua leitura e escrita a partir de um tema tão aberto a possibilidades de teorias da ciência (NOGUEIRA JÚNIOR, 2014, p.1).

Tal afirmativa, está de acordo com as opiniões emitidas sobre a intervenção pedagógica por porte dos alunos (observadas na mini redação da avaliação do projeto) como exposto abaixo:

Quando fizemos a parte escrita tivemos a oportunidade de conhecer as teorias mais a fundo, e até mesmo conhecer teorias que nunca nos foram ditas como a Panspermia e o Design Inteligente. O Debate teve seus momentos de reflexão e de discordância, pois despertou em nós o espírito de competitividade; de querer ser o melhor. Entretanto, aprendemos a respeitar as teorias diferentes das nossas, pois cada um tem seu modo de vida. Em meu ponto de vista, o debate foi bem planejado e bem trabalhado pela nossa sala, pois todos respeitaram o tempo de fala dos demais grupos (Aluno $3^{\circ}$. A).

Trabalho muito bem elaborado e organizado, que devido a colaboração de todos os grupos, serviu para maior aprendizagem. Tanto a parte escrita, quanto o debate dinâmico, colaboraram para a aprendizagem e entendimento sobre todas as teorias apresentadas nos trabalhos de cada um dos grupos (Aluno $3^{\circ}$. A).

Sobre a realização do projeto em sala de aula, tomando base nos acontecimentos em meio à sala, podemos perceber que foi bastante eficiente para a aprendizagem de todos. Começando pela parte escrita, pudemos perceber que todos adquiriram novos conhecimentos, mas o principal foi o debate, no qual opiniões são expressadas e respeitadas em nosso meio. Mas mais importante ainda, foi que todos os conceitos errados foram corrigidos, não deixando nada fora do lugar (Aluna $3^{\circ}$. A).

Projetos são importantes para melhorar o conhecimento de forma dinâmica, podendo assim, debater, tirar dúvidas e conhecer mais o conteúdo e si. Pesquisar e escrever também nos ajuda aprender e saber mais sobre o tema, pois procurando, lendo e debatendo, conseguimos entender melhor (Aluna $3^{\circ}$. A).

Tendo em vista o trabalho/projeto de intervenção sobre Origem da Vida e Teorias Evolucionistas, foi possível concluir que o mesmo trouxe diversos benefícios; com a necessidade de pesquisa para o desenvolvimento do trabalho escrito, o conhecimento de diferentes ópticas foi ampliado, resultando em um melhor poder crítico (Aluna $3^{\circ}$. B).

$\mathrm{O}$ trabalho escrito foi uma das coisas mais interessantes, pois você lendo sobre o assunto citado, adquire conhecimento sobre as teorias (Aluno $3^{\circ}$. C).

A ideia do trabalho e suas etapas foram interessantes; é um tema intrigante e de grande repercussão, sendo possível trazer bastante material a respeito e ter um debate acalorado e uma transmissão considerável de conhecimento. Levar o aluno a pesquisar e falar sobre o tema foi bom, pois ajuda, o mesmo, a redigir o tema e efetuar um debate concreto (Aluno $3^{\circ}$. C).

Contudo, ainda pode-se perceber que se faz necessário retomada de conteúdos e desenvolvimento 
de métodos de aprimoramento com relação à interpretação de textos, como observado para a questão 02 (Quadro II), que apresentou ampla porcentagem erro. Tal questão não necessitava previamente de conhecimentos aprofundados para sua resolução, sendo o bastante, interpretar de forma correta, a contextualização trazida pelo enunciado da questão. Possivelmente, esta deficiência educacional "poderia ser sanada pela exploração de ideias de um autor a partir do estudo crítico de um texto e/ou a busca de informações e exploração de ideias dos autores estudados" (ANASTASIOU; ALVES, 2004, p. 80). Salienta-se também em relação à Diretrizes Curriculares do Estado de São Paulo, que:

A capacidade de leitura e escrita que o "Currículo" determina a ser passado poderia ser um passo importante na leitura do fim do "CADERNO DO ALUNO - BIOLOGIA" da teoria do Big Ben e das fossas hidrotermais e até mesmo no texto que é que se fala da teoria dos coacervados, da sopa orgânica e da panspermia antes que a discussão tivesse início. No entanto, deveria ocupar o espaço da sala de aula, que poderia aumentar a qualidade inclusive no desenvolvimento dos alunos e do interesse deles e não no foco da quantidade como é indicado no Currículo (NOGUEIRA JR., 2014. p.32).

Com relação à questão 04 (Quadro 2), a ampla porcentagem de erros observados deve-se à defasagem do conteúdo biológico relacionado à teoria endossimbiótica, como constatado pelo professor, após retomada de conteúdo em sala de aula. Ressalta-se que esta teoria deveria ter sido enfaticamente abordada na 2a ${ }^{\text {a }}$ Série do Ensino Médio, pois constitui conteúdo importante para o entendimento por parte dos alunos das teorias da Abiogênese e Biogênese e do surgimento de seres autótrofos e heterótrofos, diretamente relacionadas aos conhecimentos à cerca de bioenergética celular (cujas melhorias foram permitidas pela endossimbiose), sendo tais postulados fatores decisivos para o entendimento posterior das Teorias de Origem da Vida e Evolucionismo (NOGUEIRA JÚNIOR., 2014).

Com relação à questão 07 (Quadro II). A elevada percentagem de erro relaciona-se, novamente, com a necessidade de melhor desenvolvimento da competência leitora em relação à interpretação de texto. Todavia, diferentemente da questão 02 , além da interpretação textual, ainda havia a necessidade de conhecimento da teoria Darwiniana da evolução das espécies para o acerto da questão. Sabe-se que a teoria Darwiniana, pode-se apresentar complexa para alunos que apresentam defasagem de conteúdo de outras teorias biológicas (MADEIRA, 2007; NOGUEIRA JÚNIOR., 2014), como citado para os erros concernentes à questão 04. Dessa forma, aconselha-se antes do início de projetos relacionados aos conteúdos Origem da Vida e Evolução a realização de diagnóstico prévio dos conteúdos relacionados à Abiogênese, Biogênese, Bioenergética Celular e Endossimbiose, a fim de otimizar a aprendizagem relacionadas a essas temáticas (NOGUEIRA JÚNIOR., 2014). Ressalta-se que "ao aprender um conteúdo, apreende-se também determinada forma de pensá-lo e de elaborá-lo, motivo pelo qual cada área exige formas de ensinar e de aprender específicas, que explicitem as respectivas lógicas" (PIMENTA; ANASTASIOU, 2002, p. 214), e que levarão subsequentemente a aquisição de novos conhecimentos e diferentes níveis de compreensão.

"A docência é caracterizada pelo desafio dos profissionais da educação em estabelecer relações interpessoais com os educandos, de modo que o processo de ensino-aprendizagem seja articulado e que os métodos utilizados cumpram os objetivos a que se propõem" (MAZZIONI, 2013, p.95). Sob este aspecto, ainda, com relação à estrutura e aplicação do projeto, relacionadas à aprendizagem, o protagonismo discente também pôde ser observado nas críticas construtivas realizadas para a melhoria da intervenção a ser promovida em anos futuros, como as explicitadas abaixo: 
Um único posicionamento sobre melhoria, seria a respeito da forma como os grupos se apresentaram, já que o grupo responsável poderia ter ido à frente da sala e realizado suas explanações para o restante dos grupos para melhor clareza de ideias (Aluno $3^{\circ}$. A)

Algumas questões podem ser levantadas em consideração à organização. A defesa das teses deveria ter siso feita de forma mais atenciosamente para informar a todos e não só o seu grupo. A estrutura das perguntas deve ser supervisionada também a fim de minimizar a perda de tempo (Aluna $3^{\circ}$. B).

Houveram algumas falhas, como argumentos sem nexo e afirmações que não batiam com a pergunta do outro, com uma discussão "moldada" de qualquer jeito. Porém com forte incentivo do professor no debate, os alunos passaram a pensar a respeito e ter um compartilhamento de ideias (Aluna $3^{\circ} . \mathrm{C}$ ).

Nota-se com tais falas que a intervenção despertou o espírito crítico nos alunos de forma salutar, pois observa-se a preocupação com a continuidade do projeto para os futuros colegas, demonstrando assim, o princípio da formação de cidadãos conscientes e responsáveis socialmente. Em suma, quando a escola desempenha seu real papel formativo, jovens tendem a desenvolver valores, competências e conhecimentos que lhes permitem a realização de escolhas responsáveis em suas vidas sociais (RIBEIRO et al., 2013).

\section{CONCLUSÃO}

A intervenção pedagógica realizada propiciou uma aprendizagem ativa por meio da utilização das metodologias de Ensino em Grupos e Discussões e Debates, promovendo com dinamismo, eficiência e eficácia conhecimentos sobre os temas origem da vida (Criacionismo, Panspermia, Design Inteligente) e Evolucionismo (Lamarckismo, Darwinismo e Neodarwinismo ou Teoria Sintética da Evolução). Também, notou-se ao final do projeto melhoria nas competências de Leitura e Escrita. Contudo, ainda há necessidade de se aprofundar técnicas de interpretação de texto com os discentes. Os partícipes do projeto também demonstraram preocupação com a continuidade do projeto para os futuros colegas, evidenciando, princípios norteadores de cidadãos conscientes e responsáveis socialmente.

\section{REFERÊNCIAS}

ANASTASIOU, L. G. C.; ALVES, L. P. Estratégias de ensinagem. In: ANASTASIOU, L. G. C.; ALVES, L. P. (Orgs.). Processos de ensinagem na universidade. Pressupostos para as estratégias de trabalho em aula. 3. ed. Joinville: Univille, 2004. Pp. 67-100.

ASTOLFI, J. P.; DEVELAY, M. Didática das Ciências. Campinas: Ed. Papirus. 1995.

BRASIL. Parâmetros Curriculares Nacionais para o Ensino Médio: Parte I - Bases Legais. Brasília. 1999.

CARMAGO, D. R. de. Os conceitos de sustentabilidade e de desenvolvimento sustentável na produção teórica em educação ambiental no Brasil: um estudo a partir de teses e dissertações. 2016. 195f. Dissertação (mestrado) - Universidade Estadual Paulista - UNESP., Instituto de Biociências de Rio Claro. Rio Claro, SP. 
LUCKESI, C. C. Filosofia da educação. São Paulo: Cortez, 1994

MARION, J. C.; MARION, A. L. C. Metodologias de ensino na área de negócios. Para cursos de administração, gestão, contabilidade e MBA. São Paulo: Atlas, 2006.

MARTINS, A. M. Diretrizes curriculares nacionais para o ensino médio: avaliação de documento. Cadernos de Pesquisa, v. 109, p. 67-87, 2000.

MARTINS, M. V. Quando uma sociologia da ciência se faz necessária: aspectos contemporâneos do embate entre criacionistas e evolucionistas. Filosofia e História da Biologia, v. 8, n. 2, p. 279-299. 2013.

MAZZIONI, S. As estratégias utilizadas no processo de ensino-aprendizagem: concepções de alunos e professores de Ciências Contábeis. Revista Eletrônica de Administração e Turismo - ReAT, v. 2, n. 1, 2013.

MENDONÇA, F. B. et al. Proposta Curricular do Estado de São Paulo: Biologia. São Paulo: Secretaria da Educação do Estado de São Paulo - SEE. 2008. 44p.

NOGUEIRA JR. G. A origem da vida: por entre estudos e saberes escolares. 2014. 36f. Trabalho de conclusão de curso (Licenciatura - Ciências Biológicas) - Universidade Estadual Paulista, Instituto de Biociências de Rio Claro, Rio Claro, SP.

PEDROSO-DE-MORAES, C. et al. Prática de campo: aprendizagem sobre biodiversidade e preservação ambiental verificada em discentes da Escola Estadual Pirassununga, SP. Nucleus, v.12, p. 361-369. 2015.

PEDROSO-DE-MORAES, Cristiano et al. Análise de intervenção interdisciplinar no $1^{\circ}$. ano do ensino médio da Escola Estadual Pirassununga, SP.. Nucleus, Ituverava, v. 13, n. 2, p. 17-32, nov. 2016. ISSN 1982-2278. Disponível em:

<http://www.nucleus.feituverava.com.br/index.php/nucleus/article/view/1595/2115>. Acesso em: 14 may 2018. doi:http://dx.doi.org/10.3738/1982.2278.1595.

PETRUCCI, V. B. C.; BATISTON, R. R. Estratégias de ensino e avaliação de aprendizagem em contabilidade. In: PELEIAS, I. R. (Org.) Didática do ensino da contabilidade. São Paulo: Saraiva, 2006.

PIMENTA, S. G.; ANASTASIOU, L. G. C. Docência no ensino superior. São Paulo: Cortez, 2002.

RIBEIRO, J.; PONTES, A.; SANTOS, L. Conceção e implementação de um projeto de educação sexual na turma: legislação vs literatura. Revista Lusófona de Educação, v.23, p.179-198, 2013.

SAVIANI, D._Saber escolar, currículo e didática: problemas da unidade conteúdo/método no processo pedagógico. Campinas, SP: Autores Associados, 2003. 200 p.

SENICIATO, T.; CASSAVAN, O. Aulas de campo em ambientes naturais e aprendizagem em ciências um estudo com alunos do fundamental. Ciência \& Educação, v. 10, p. 133-147, 2004.

SILVA, L. F.; CARVALHO, L. M. A Temática ambiental e o ensino de Física na escola média: algumas possibilidades de desenvolver o tema produção de energia elétrica em larga escala em uma situação de ensino. Revista Brasileira de Ensino Física, v. 24, p. 342-352, 2002.

SILVA, L. L. da; DINIZ, E. M.; PEDROSO-DE-MORAES, C. Análise da percepção ambiental de um grupo de alunos com necessidades educacionais especiais educacionais. Revista Científica da FHO|UNIARARAS, v. 2, p. 1-9, 2014.

THIOLLENT, M. Metodologia da pesquisa-ação. 10. ed. São Paulo: Autores Associados, 2000. 235p. 
